\title{
Preparation and Properties of Hydroxyapatite/Methylcellulose for Bone Graft
}

\author{
Woo-Seong Tak*, Dong-Jun Kim*, and Su-Chak Ryu**, \\ *Department of Nano Fusion Technology, Pusan National University, Miryang 50463, Korea \\ **Department of Nanomechatronics, Pusan National University, Busan 46241, Korea
}

(Received November 1, 2017; Revised February 28, 2018; Accepted March 16, 2018)

\begin{abstract}
Although many bone graft materials have been developed, powder graft materials are somewhat difficult to use in surgery. To solve this problem, a bone graft material in the form of a viscous paste was prepared. Hydroxyapatite was used as a bone graft material, and methyl cellulose was used to impart viscosity. Three cases of samples were prepared, and freeze-dried block type and sintered specimens were made from the paste. The recrystallization of the graft material in a simulated body fluid and the degree of graft adhesion with a tooth were observed by scanning electron microscopy (SEM). The test for cytotoxicity was carried out and the sample was grafted into the back of a mouse to confirm the presence or absence of side effects in the animal's body. Based on these investigations, composites of this type are expected to be applicable for bone grafts.
\end{abstract}

Key words : Hydroxyapatite, Methylcellulose, Freeze-drying, Paste, Rats

\section{Introduction}

0 wing to bone defects, the need for bone grafts has increased. Bone grafts are categorized as autografts, allografts, xenografts, and synthetic bone grafts. The autograft is the ideal bone graft material. Because it is taken from the patient themselves, there is no immune reaction and it has all the properties of osteogenesis, osteoinduction, and osteoconduction., ${ }^{1,2)}$ Despite these benefits, it cannot always be used as the available volume is limited and the patient may suffer side effects due to the harvesting of material from another site on their body. Allografts are harvested from cadavers, so material is more readily available in terms of quantity, but it may cause infection or immune responses. ${ }^{3-7)}$ Xenografts, collected from cattle, pigs, corals, and other organisms, have osteoconduction and are cheap and available in unlimited quantity, but they can cause immune reaction and do not achieve good synostosis. ${ }^{4-7}$ Because the synthetic bone substitutes are synthetic materials, they are available in unlimited quantity and there are no concerns about immune response.8) They also have the property of osteoconduction. A bone graft should have a similar structure with natural bone. There are many synthetic bone substitutes including calcium phosphate, beta-tricalcium phosphate, and hydroxyapatite., ${ }^{2,-11)}$ Among them, hydroxyapatite is most similar in structure with natural bone, as many studies have proven. ${ }^{12-14)}$ These bone grafts have been used in the form of powders, which are inconve-

\footnotetext{
Corresponding author: Su-Chak Ryu

E-mail : scryu@pusan.ac.kr

Tel : +82-55-350-5276 Fax : +82-55-350-5299
}

nient to insert during surgery.

To overcome the inconvenience of using powders, the materials with viscosity are required. Methylcellulose is a nontoxic and biodegradable polymer, used for various purposes including nutritional capsules, tooth paste, artificial tears, and supplements to culture stem cells. ${ }^{15-17)}$ This means that methylcellulose is verified to be harmless to humans. One of its properties is a low critical solution temperature, between $40-50^{\circ} \mathrm{C}$. Below this temperature, it has unlimited solubility and forms a single phase with water.

Samples made by mixing hydroxyapatite powder and methylcellulose solution were evaluated for mechanical properties. Viscosity tests were carried out to find the optimal mixing ratio for convenient handling. Sample surfaces were observed in order to determine pore size and distribution after the sintering process. Apparent porosity, apparent specific gravity, water absorption ratio, and bulk specific gravity were also measured. Samples inserted in teeth and freeze-dried samples were also processed to check hardness after soaking in simulated body fluid for certain periods.

\section{Experimental Procedure}

\subsection{Fabrication of composite and measurement of viscosity}

Entire fabrication process is simply shown in Fig. 1. The sample was prepared in the form of a paste by mixing hydroxyapatite (HAp) powder, methylcellulose (MC), and distilled water (DI water) using a paste mixer (PDM-300, Daewha Tech, Rep. of Korea). The particle size of the powder was $45 \mu \mathrm{m}$. The DI water was heated above $70^{\circ} \mathrm{C}$ and poured into a container holding the HAp and MC. After 
Table 1. Ratios of Components in Composite

\begin{tabular}{cccc}
\hline MC solution & & & \\
HAp : MC & & & $9 \%$ \\
\hline $100: 3$ & Sample 1 & Sample 2 & Sample 3 \\
$100: 5$ & Sample 4 & Sample 5 & Sample 6 \\
$100: 7$ & Sample 7 & Sample 8 & Sample 9 \\
\hline
\end{tabular}

Table 2. True Weights of Components

\begin{tabular}{cccc}
\hline & Hap & MC & DI water \\
\hline Sample 1 & $100 \mathrm{~g}$ & $3 \mathrm{~g}$ & $57 \mathrm{~g}$ \\
Sample 2 & $100 \mathrm{~g}$ & $3 \mathrm{~g}$ & $39.86 \mathrm{~g}$ \\
Sample 3 & $100 \mathrm{~g}$ & $3 \mathrm{~g}$ & $30.33 \mathrm{~g}$ \\
Sample 4 & $100 \mathrm{~g}$ & $5 \mathrm{~g}$ & $95 \mathrm{~g}$ \\
Sample 5 & $100 \mathrm{~g}$ & $5 \mathrm{~g}$ & $66.42 \mathrm{~g}$ \\
Sample 6 & $100 \mathrm{~g}$ & $5 \mathrm{~g}$ & $50.56 \mathrm{~g}$ \\
Sample 7 & $100 \mathrm{~g}$ & $9 \mathrm{~g}$ & $133 \mathrm{~g}$ \\
Sample 8 & $100 \mathrm{~g}$ & $9 \mathrm{~g}$ & $93 \mathrm{~g}$ \\
Sample 9 & $100 \mathrm{~g}$ & $9 \mathrm{~g}$ & $70.77 \mathrm{~g}$ \\
\hline
\end{tabular}

mixing using the paste mixer, it was cooled to room temperature. The viscosities of the pastes were measured using a digital viscometer (DV2T, Brookfield, USA) in order to select the ideal ratio with moderate viscosity and good workability by hand. The HAp:MC ratios of the samples are stated in Table 1. Table 2 inform the real weights of components in accordance with Table 1 . When the $10 \%$ concentra-

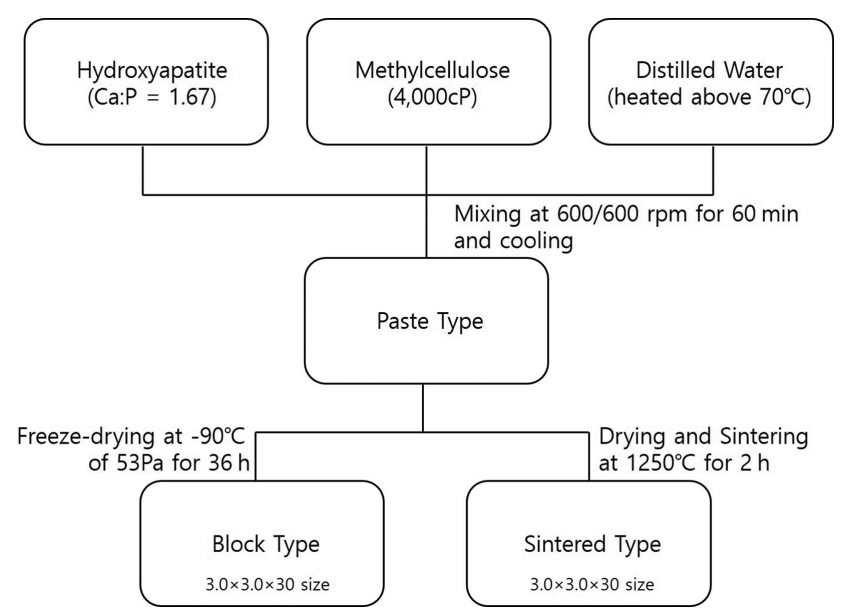

Fig. 1. Fabrication process of grafts.

tion MC solution was used in the ratio $100: 3$, viscosity of the sample was too high and not castable to prevent testing using viscometer that is rotational tester. Therefore, MC concentration over $9 \%$ does not make the composite castable at a certain ratio and this concentration was not considered.

The sample selected in the viscosity test was freeze-dried at $-90^{\circ} \mathrm{C}$ and a pressure of $53 \mathrm{~Pa}$ for $36 \mathrm{~h}$. The sample dimensions were $3.0 \times 3.0 \times 30 \mathrm{~mm}$. The freeze-dried sample blocks were soaked for 4,8 , and 12 weeks in simulated body fluid (SBF, Biosesang, Rep. of Korea) to observe surface activation and to test hardness. For sintering, the paste samples $3.0 \times 3.0 \times 30 \mathrm{~mm}$ in size were dried in a glass case and then heat treated at $700^{\circ} \mathrm{C}$ for $2 \mathrm{~h}$ and $1250^{\circ} \mathrm{C}$ for $2 \mathrm{~h}$ with a cooling and heating rate of $5^{\circ} \mathrm{C} / \mathrm{min}$.

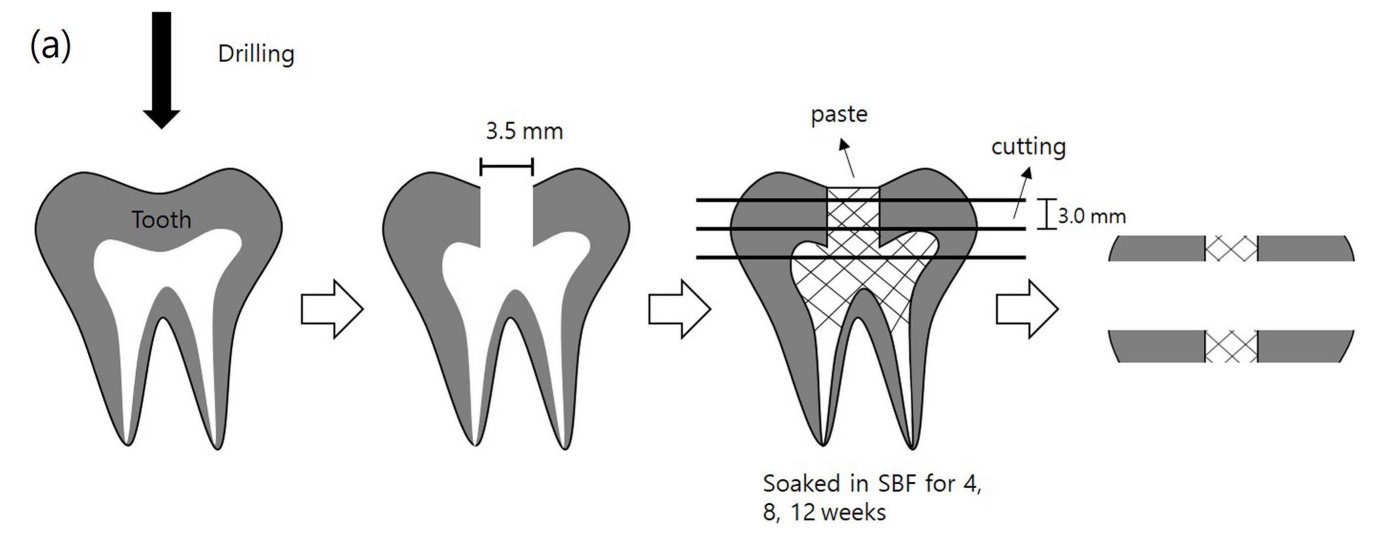

(b)

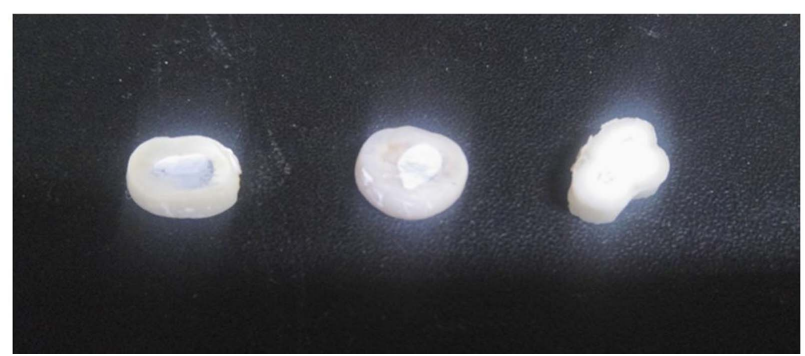

Fig. 2. (a) Tooth injection and insertion of sample (b) Actual image of cut tooth injection sample. 


\subsection{Preparation of Tooth Injection}

To verify adhesion between teeth and the paste sample, extracted teeth were prepared. Holes $3.5 \mathrm{~mm}$ in diameter were drilled in the teeth as shown in Fig. 2(a). The pastes were inserted in the holes in the teeth.

\subsection{Surface activation and Hardness}

After the sample blocks had been soaked in SBF for 4, 8, and 12 weeks, they were observed using a field emission scanning electron microscope (FE-SEM) (S-4700, Hitachi, Japan). To investigate the correlation between surface activation and hardness, the hardness was measured with a micro-Vickers hardness tester (TH-710, Time, China). The specimen was cut to a thickness of $3 \mathrm{~mm}$ and tested on an uncut surface. In addition, to determine the degree of adhesion of the tooth and paste after soaking in SBF, the tooth injected samples were soaked in SBF for 4,8 , and 12 weeks. As with the blocks, the teeth were cut to a thickness of precisely $3 \mathrm{~mm}$ using a low-speed cutter (IsoMet LS, Buehler, Switzerland), with a $0.3 \mathrm{~mm}$ thick diamond blade. Both the $\mathrm{HAp} / \mathrm{MC}$ sample region and the tooth region were tested using a micro-Vickers hardness tester. The hardness test area is shown in red in Fig. 3(a). Then, FE-SEM was used to examine the degree of adhesion between tooth and HAp/MC paste.

\subsection{Properties of sintered samples}

The sintered samples were tested for tensile strength using a universal material testing machine (SM Tester, Rep. of Korea). The test was performed on five specimens for each sample. The speed of the machine was set to $2 \mathrm{~mm} /$ $\min$.

Additionally, apparent porosity, water absorption, apparent specific gravity, and bulk specific gravity were measured using Archimedes' principle. The samples were absolutely dried in an incubator at $110^{\circ} \mathrm{C}$ overnight. The dried sample was weighed in an electronic balance. This weight was designated as $\mathrm{W}_{1}$. The samples were then immersed in boiling DI water for longer than $3 \mathrm{~h}$ and cooled to room temperature. Next, they were suspended with wire that was less than $1 \mathrm{~mm}$ in diameter and were weighed in DI water. This weight, with the weight of the wire subtracted, was called $\mathrm{W}_{2}$. The samples were wiped dry with fabric and again weighed to determine $\mathrm{W}_{3}$. The properties were calculated according to the below equations.

Apparent porosity:

$\mathrm{P}_{\mathrm{o}}=\left(\mathrm{W}_{3}-\mathrm{W}_{1}\right) /\left(\mathrm{W}_{3}-\mathrm{W}_{2}\right) \times 100(\%)$,

Water absorption:

$\mathrm{A}_{\mathrm{w}}=\left(\mathrm{W}_{3}-\mathrm{W}_{1}\right) / \mathrm{W}_{1} \times 100(\%)$

Apparent specific gravity:

$\mathrm{D}_{\mathrm{a}}=\mathrm{W}_{1} /\left(\mathrm{W}_{1}-\mathrm{W}_{2}\right)$,

Bulk specific gravity:

$\mathrm{D}_{\mathrm{b}}=\mathrm{W}_{1} /\left(\mathrm{W}_{3}-\mathrm{W}_{2}\right)$

\section{5. pH test}

A $\mathrm{pH}$ test was carried out to evaluate the MC/HAp composite. A $4 \mathrm{~g}$ specimen of each sample was soaked in $20 \mathrm{ml}$ of DI water in a $50^{\circ} \mathrm{C}$ incubator for $72 \mathrm{~h}$. The water decanted was centrifuged at $1000 \mathrm{rpm}$ for $5 \mathrm{~min}$. Ten $\mathrm{ml}$ of supernatant was mixed with $0.5 \mathrm{ml}$ of $\mathrm{KOH}$ solution $(1 \mathrm{~g} / \mathrm{L})$. The $\mathrm{pH}$ was measured using a digital pH meter (S20 Seven Easy, Mettler Toledo, USA) at $25^{\circ} \mathrm{C}$. A similar test was carried out on samples soaked in SBF. (a)

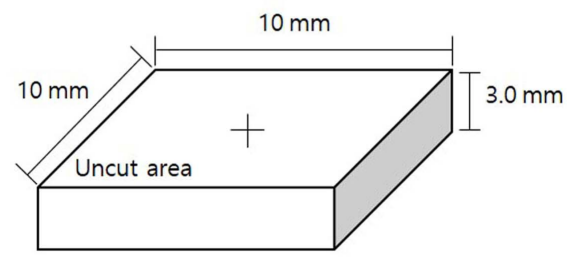

(b)
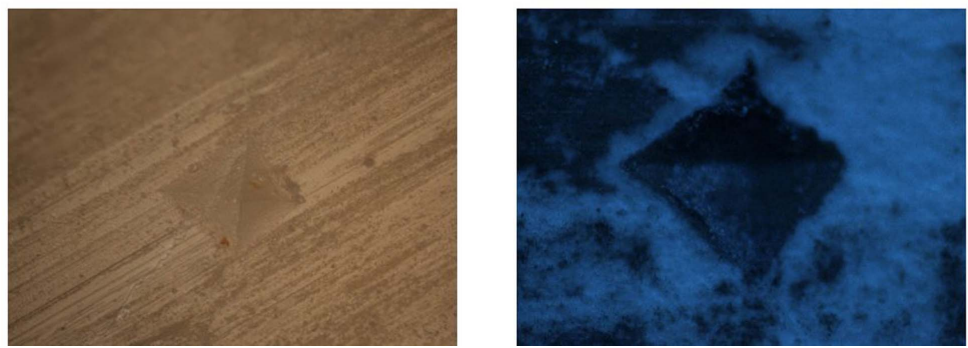

Fig. 3. (a) Hardness test locations (b) Indentation impression of the test sample. 


\subsection{Cell culture}

Culture medium was prepared by mixing Dulbecco's modified Eagle's medium (Sigma-Aldrich, USA), 10\% fetal bovine serum (SAFC, USA), and 1\% penicillin-streptomycin (Gibco, USA). The MG-63 cell line (ATCC, USA) was used, and was harvested from the culture medium in a T-75 flask. Culturing was maintained at $37^{\circ} \mathrm{C}$ in an incubator of $5 \%$ $\mathrm{CO}_{2}$ and $95 \%$ air (Ws-40ca, World Science, Rep. of Korea). The medium was changed every $48 \mathrm{~h}$ and the dish was washed with phosphate buffer saline (PBS; Gibco, USA). The cell culture used in this study was between the sixth and ninth passages.

\subsection{Cell cytotoxicity}

A cell suspension was made to $1 \times 10^{5} / \mathrm{ml}$ concentration and $100 \mu \mathrm{l}$ of the suspension was seeded to each well of a 96 well dish, and it was cultured in an incubator of $5 \% \mathrm{CO}_{2}$ at $37^{\circ} \mathrm{C}$ for $24 \mathrm{~h}$. At the same time, negative control, positive control, control, and experiment groups were made. For the negative control, positive control, and experiment groups, $30 \mathrm{~cm}^{2}$ of high density polypropylene (Hatano Research Institution, Japan), $0.5 \mathrm{~g}$ of natural rubber latex (Microflex, Belgium), and $0.5 \mathrm{~g}$ of the freeze-dried sample were soaked in $5 \mathrm{ml}$ of culture medium in conical tubes respectively. The control group was culture medium with no additive. They were placed in a $37^{\circ} \mathrm{C}$ incubator with $5 \% \mathrm{CO}_{2}$ for $24 \mathrm{~h}$. Thereafter, the medium in the wells was removed and the wells were washed with PBS. The wells were changed with above groups. The dish was placed in incubator of $5 \% \mathrm{CO}_{2}$ at $37^{\circ} \mathrm{C}$ for $24 \mathrm{~h}$. Then $100 \mu \mathrm{l}$ of EZ-cytox (DoGenBio. Co., Ltd, Rep. of Korea) was added to each well and the dish was again placed in incubator of $5 \% \mathrm{CO}_{2}$ at $37^{\circ} \mathrm{C}$ for $1 \mathrm{~h}$. Thereafter, light absorbance at $450 \mathrm{~nm}$ was measured using a multilabel plate reader (Victor 3, PerkinElmer, USA).

\subsection{In vivo experiment}

Each rat was given an intramuscular injection with ketamine hydrochloride of $70 \mathrm{mg} / \mathrm{kg}$ concentration. After their fur was shaved, they were disinfected with povidone iodine and were fixed. The surgical parts were under infiltration anesthesia using 2\% lidocaine with 1 : 80,000 epinephrine, and on the back subcutaneous incisions were made at two regions $20 \mathrm{~mm}$ apart. A $10 \mathrm{~mm}$ diameter $\times 1 \mathrm{~mm}$ high specimen of the freeze-dried sample was implanted on the hypodermis. The parts were sutured with 4 - 0 monosyn, taking care not to suture membrane and skin together. At a week, the skin over the inserted part was observed with the naked eye. At 2 weeks, the rats were sacrificed and the surgical parts were cut. All processes of the animal experiment proceeded in the Pusan National University Laboratory Animal Resources Center, and the protocol was approved by the Pusan National University Institutional Animal Care and Use Committee.

\section{Results and Discussion}

\subsection{Choice of ratio}

The results of the viscosity measurements are shown in Fig. 4. Viscosity can be seen to increase with the amount of HAp added to the MC. A paste that could stand vertically without slumping was desired, and by that standard, sample 2 was appropriate.

\subsection{Activation in simulated body fluid}

For 4, 8, and 12 weeks, the freeze-dried samples were immersed in SBF in order to investigate the effect of period of immersion. In Fig. 5(a), projections can be found on the surfaces of particles. These projections are regarded as nuclei of apatite. Because this is the beginning of the formation of apatite nuclei, the surface seems to be rough like a hilly landscape. Since the SBF itself was neutral in the initial stage of immersion, the phosphate ions in the solution were present as $\mathrm{H}_{2} \mathrm{PO}_{4}{ }^{3-}$ and $\mathrm{HPO}_{4}{ }^{2-}$, so that calcium ions and hydrogen phosphate ions in the solution reacted according to reaction 1 in Fig. 6. Because of the elution of hydroxyapatite, the solution becomes strongly alkaline with a $\mathrm{pH}$ of

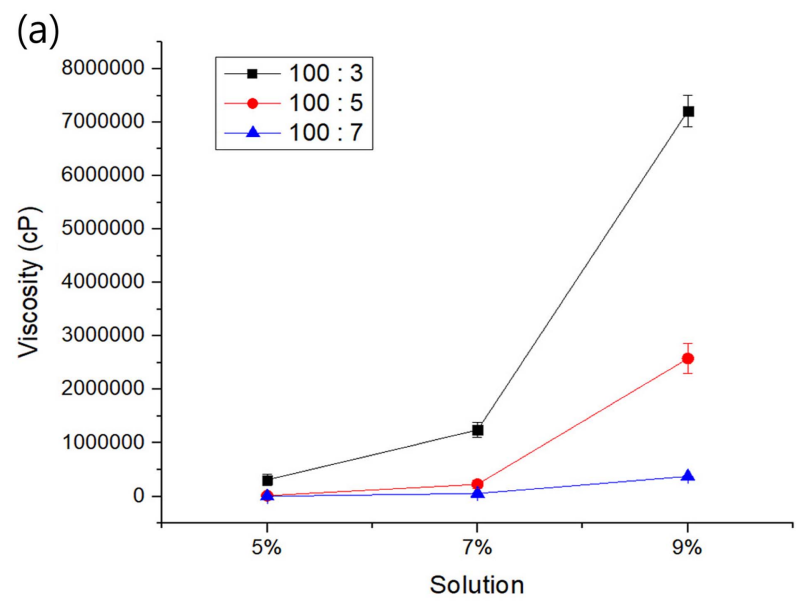

\begin{tabular}{|l|r|}
\cline { 2 - 2 } (b) & \multicolumn{1}{|c|}{ Viscosity (cP) } \\
\cline { 2 - 3 } Sample 1 & 307,733 \\
\hline Sample 2 & $1,241,000$ \\
\hline Sample 3 & $7,213,500$ \\
\hline Sample 4 & 12,160 \\
\hline Sample 5 & 225,000 \\
\hline Sample 6 & $2,578,800$ \\
\hline Sample 7 & 1,760 \\
\hline Sample 8 & 52,960 \\
\hline Sample 9 & 373,600 \\
\hline
\end{tabular}

Fig. 4. (a) Graph of viscosity (b) Viscosity results of samples. 


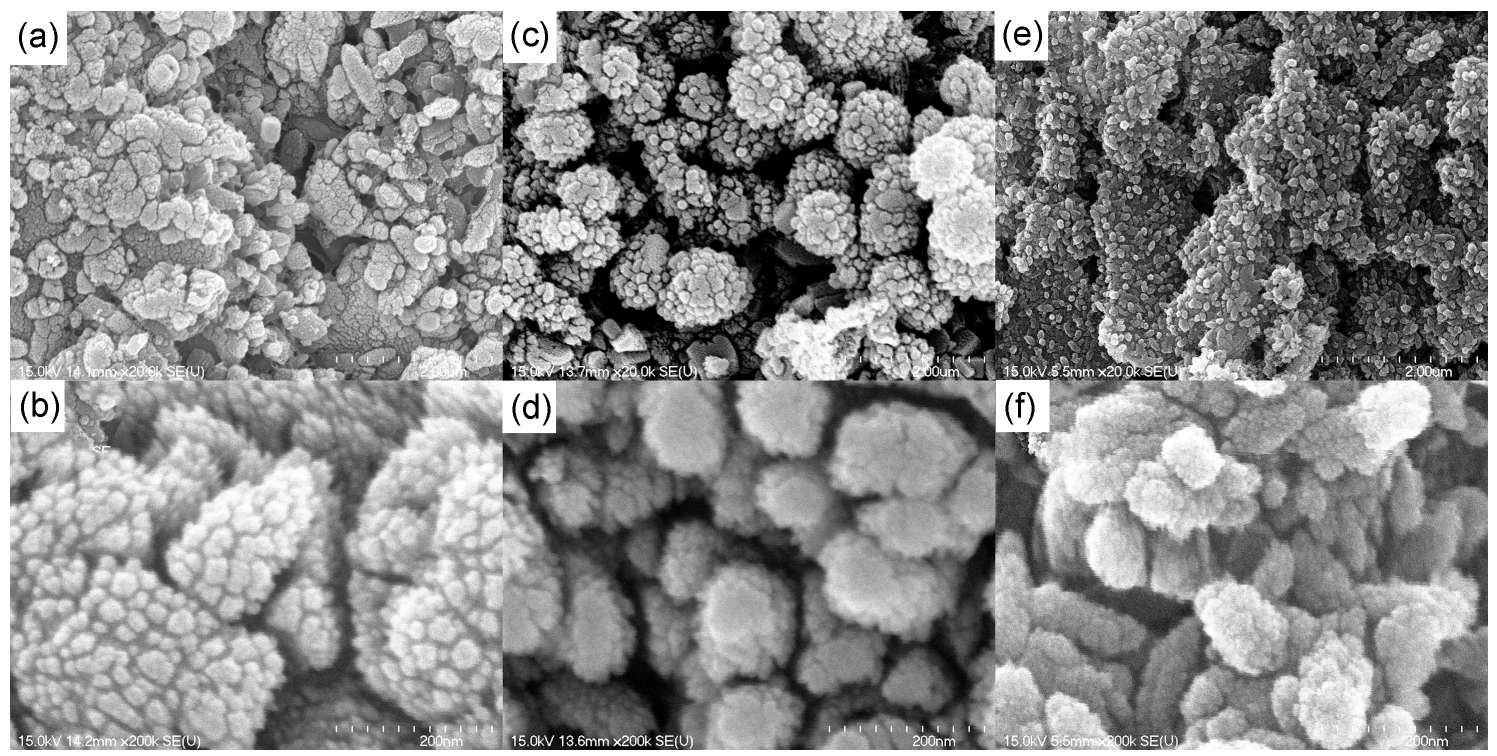

Fig. 5. SEM image of specimen in SBF (a) $20 \mathrm{k}$, (b) $200 \mathrm{k}$ at 4 weeks, (c) $20 \mathrm{k}$, (d) $200 \mathrm{k}$ at 8 weeks, and (e) $20 \mathrm{k}$, (f) $200 \mathrm{k}$ at 12 weeks.

In Simulated Body Fluid

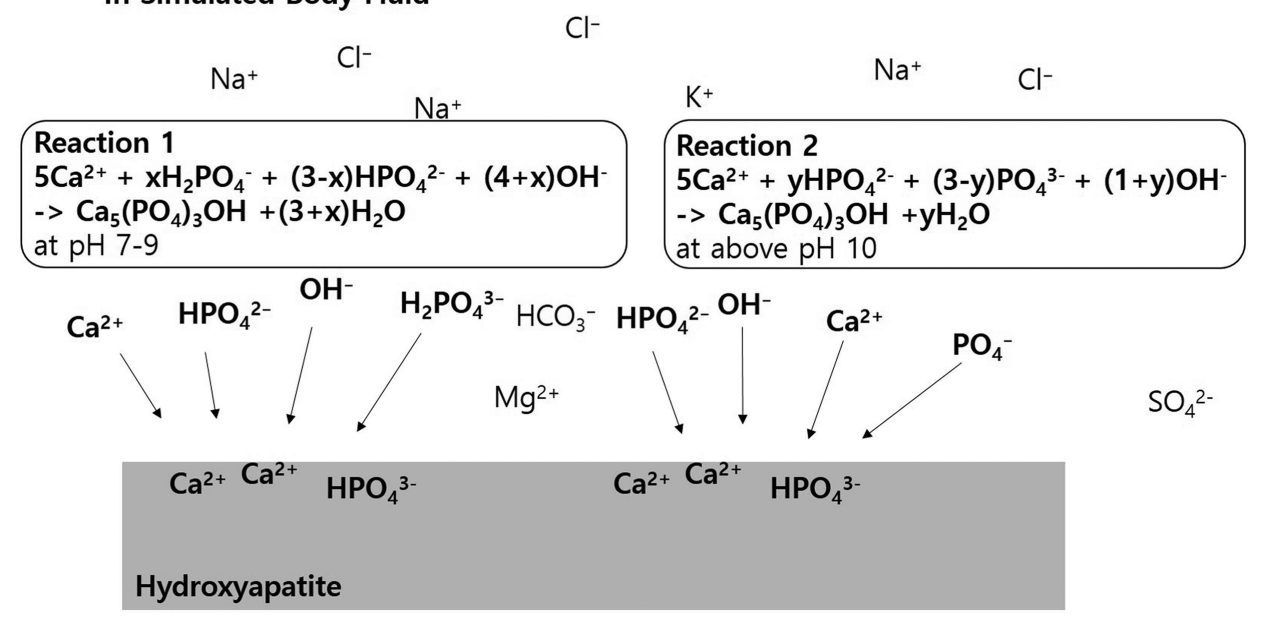

Fig. 6. Mechanism of activation in SBF.

12 and the phosphate ions take the forms of $\mathrm{HPO}^{4-}$ and $\mathrm{PO}_{4}{ }^{3-}$ as in reaction 2 in Fig. 6. Phosphate ions are present in the form of $\mathrm{HPO}^{4-}$ and $\mathrm{PO}_{4}{ }^{3-}$ at $\mathrm{pH}$ above 10 and $\mathrm{H}_{\mathrm{P}} \mathrm{O}_{4}{ }^{3-}$ and $\mathrm{HPO}_{4}{ }^{2-}$ at $\mathrm{pH}$ of $5-9$. The nuclei grow with time in the SBF. Hiroyuki Shibata et al. (2013, p 807-812) obtained the same XRD peaks from crystals grown in SBF solution and from hydroxyapatite. ${ }^{18)}$ In Fig. 5(b), the nuclei were observed to have grown slightly. In 12 weeks, the nuclei can be seen to have grown into particles. Initial hydroxyapatite particles present at the beginning can no longer be found, indicating that this material in the body can promote bone regeneration.

The tooth injection specimens were soaked for 4, 8, and 12 weeks to view the degree of adhesion between sample and tooth. Fig. 7 shows the horizon between tooth and composite. At 4 weeks, there is some adhesion, but gaps can be easily seen between sample and tooth. There are also gaps in the middle of the sample. In 8 weeks, cracks can still be recognized but their degree is diminished. By 12 weeks, large gaps do not exist and the adhesion is almost complete. It is presumed that 12 weeks is sufficient for the development of adhesion between tooth and bone graft materials.

To determine the correlation between SBF activation and hardness, the hardness test was performed using the microVickers hardness tester. Fig. 8 shows that the hardness values are proportional to immersion time in the SBF. The reason is presumably that pores and voids were filled with hydroxyapatite newly formed in SBF. Note that the hardness result a sample injected in a tooth is lower than that of a block type sample. It is reasonable to assume that more of the block type sample is directly faced with SBF than is the injected sample so that the injected sample had a smaller amount of material for recrystallization than did the block type. This led to a difference of hardness between the block 


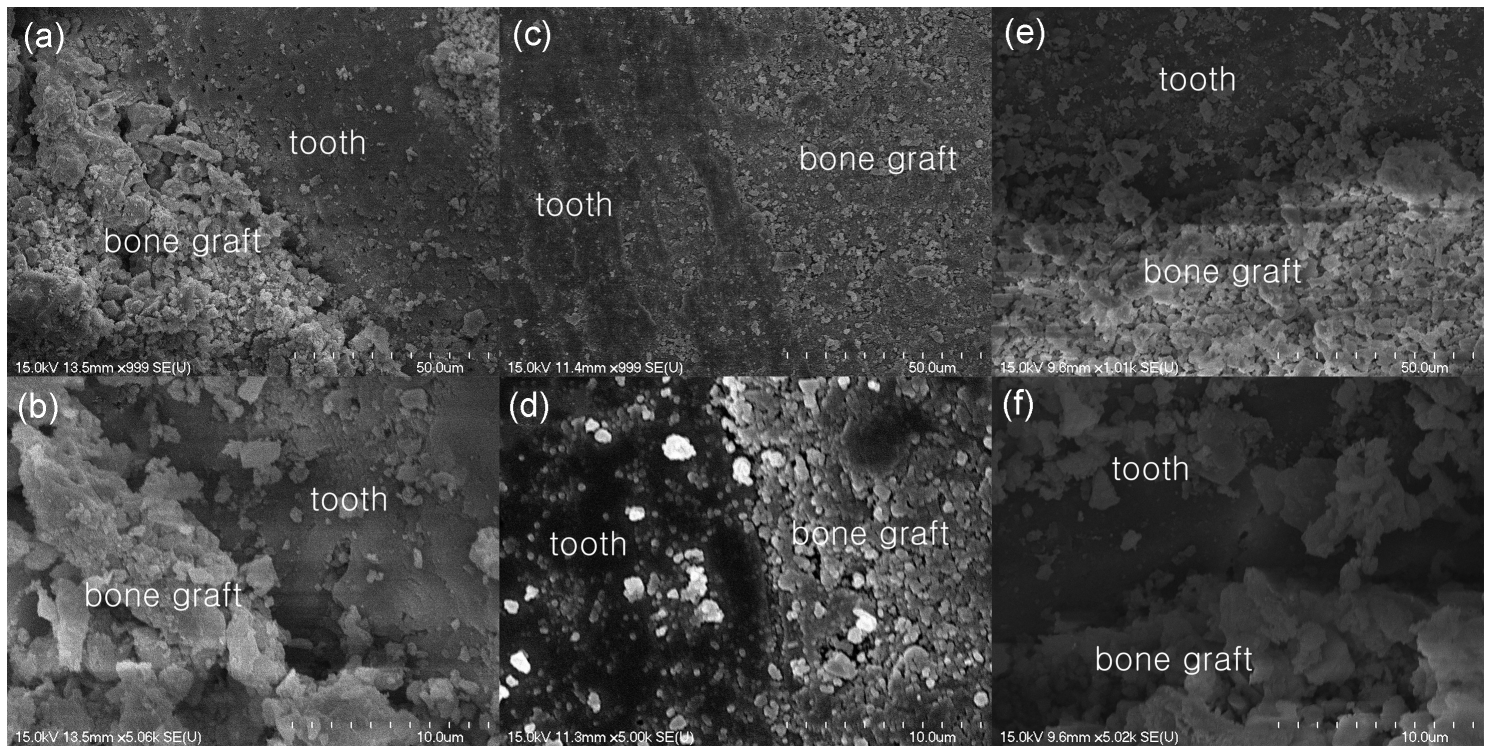

Fig. 7. Adhesion between tooth and composite in SBF (a) $1.0 \mathrm{k}$ (b) $5.0 \mathrm{k}$ at 4 weeks, (c) $1.0 \mathrm{k}$, (d) $5.0 \mathrm{k}$ at 8 weeks, and (e) $1.0 \mathrm{k}$, (f) $5.0 \mathrm{k}$ at $12 \mathrm{weeks}$.

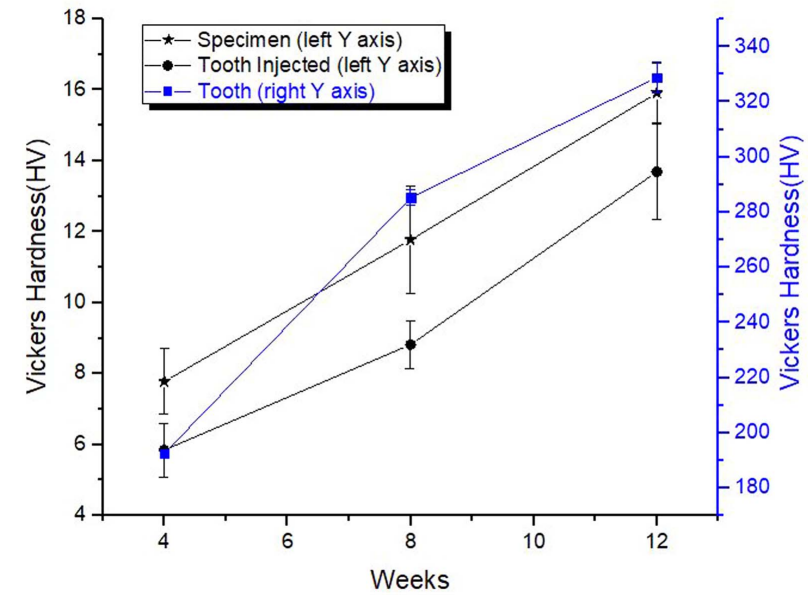

Fig. 8. Vickers hardness of composite and sample injected in tooth.

(a)

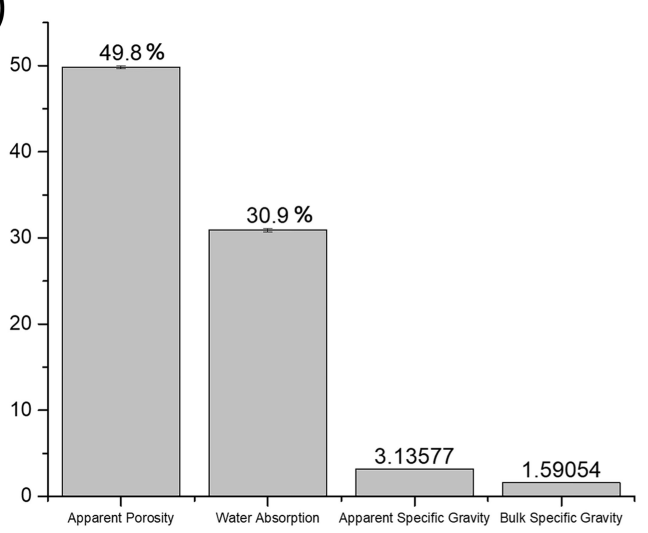

type and the injected sample. However, compared to the tooth, the hardness of the sample showed a very low value. This is presumably due to the very high density of the enamel. As with the sample, the tooth also increased in hardness over time. It is considered that phosphoric acid and calcium components in the simulated body fluid react with hydroxyapatite or fluorapatite of the enamel to effect recrystallization.

After heat treatment, porosity, water absorption, and specific gravity was measured. The size of the sintered sample was about $9.77 \times 9.77 \times 29.4 \mathrm{~mm}$ and the shrinkage was about $6.4 \%$. In the sample, the total weight of MC and DI water was $42.86 \mathrm{~g}$ with $100 \mathrm{~g}$ of hydroxyapatite. Though the weight loss was less a half of the sample weight, apparent porosity was $49.8 \%$. True porosity seems to be far greater than apparent porosity. This is a large porosity value, allowing for densification caused by sintering. The reason can be found in the process. In freeze-drying, the bulk of water in

(b)

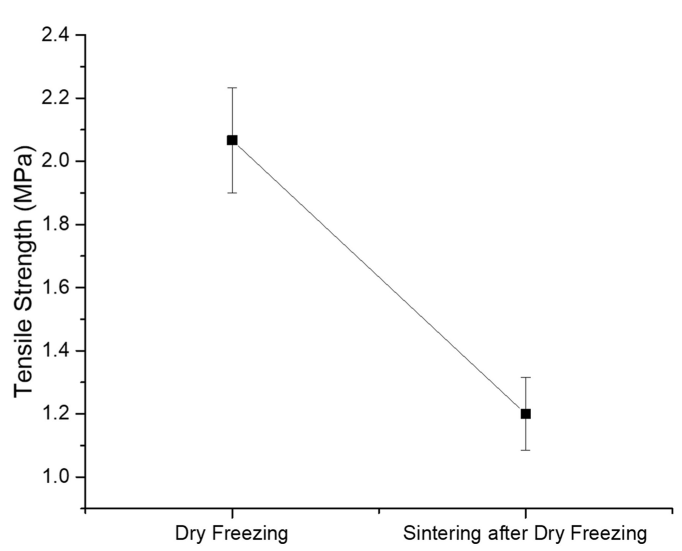

Fig. 9. (a) Apparent porosity, water absorption, apparent specific gravity, and bulk specific gravity of sintered composite (b) Tensile strength of freeze dried and sintered composite. 


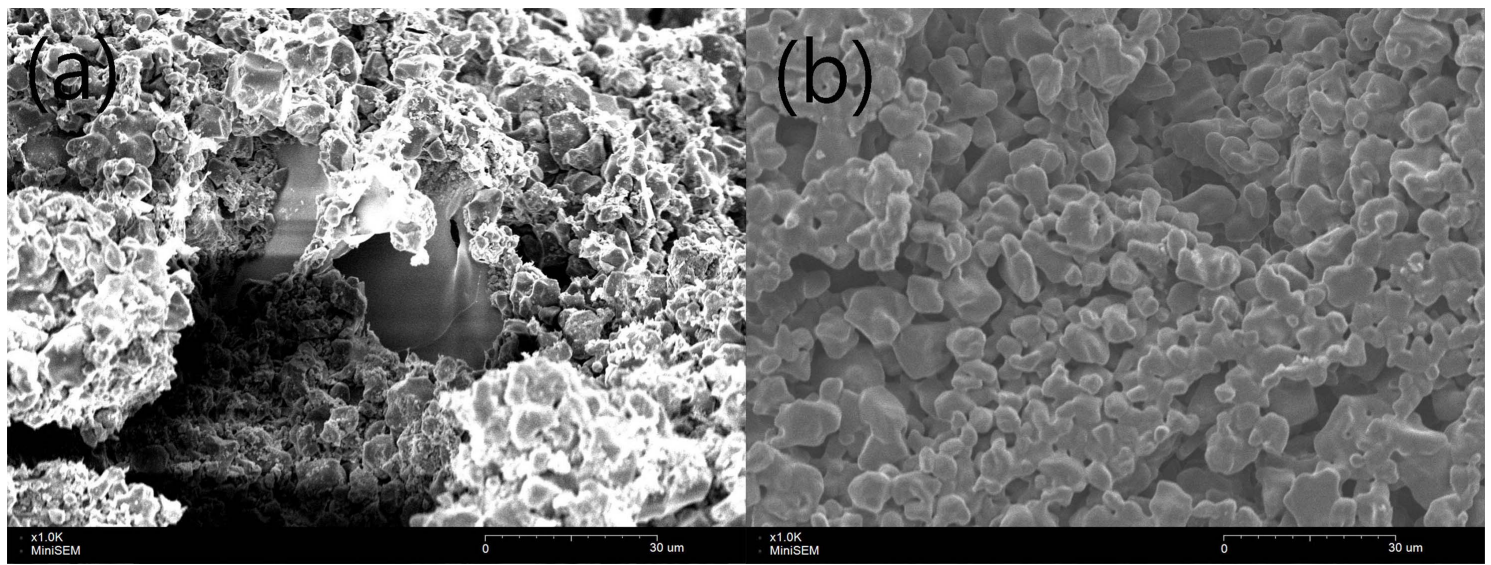

Fig. 10. Microstructure of (a) Freeze-dried and (b) sintered composite.

the sample became larger leading to an increase in porosity. The water absorption was $30.9 \%$. The apparent specific gravity was 3.13577 and the bulk specific gravity was 1.59054. The two differ because the latter value includes the open porosity and the former does not.

Tensile strength was tested for two kinds of sample, the freeze-dried sample and the sintered sample. The results are shown in Fig. 9(b). It was predicted that tensile strength of the sintered sample would be higher than that of the freeze-dried sample, but the result was the reverse. This suggests that the MC polymer filling the voids between hydroxyapatite grains supports the applied force. As can be seen from Fig. 10, the sintered sample has many voids, but in the freeze-dried sample MC forms a network.

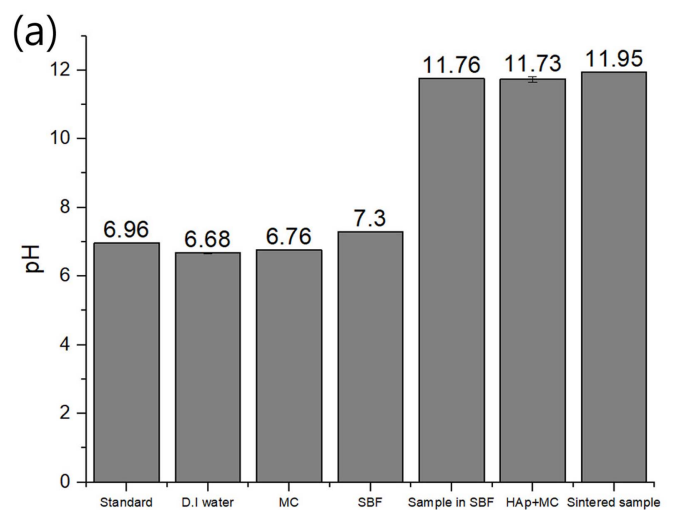

\section{3. pH test}

As shown Fig. 11(a), the results imply that MC's pH result is similar to that of DI water and harmless to the body in regard to $\mathrm{pH}$. The elutions of both the HAp/MC composite and the sintered composite without MC were strongly alkaline and the composite could therefore cause diverse side effects.

\subsection{Cell cytotoxicity}

Considering the above $\mathrm{pH}$ results, cytotoxicity was expected, but the results show good cell viability of over $80 \%$ in Fig. 11(b). The composite can therefore be proven to be non-cytotoxic.

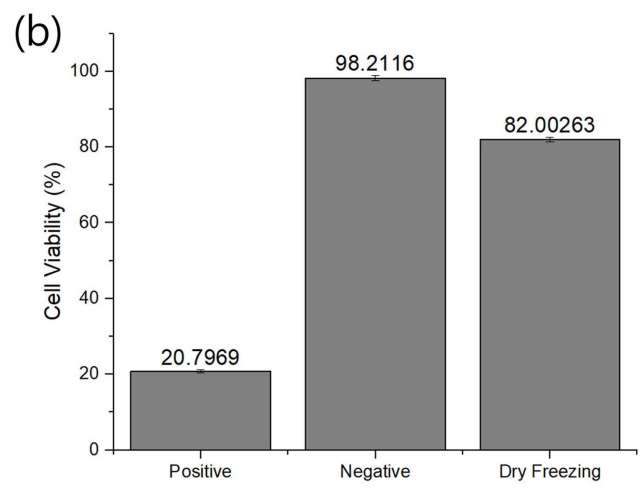

Fig. 11. (a) Results of $\mathrm{pH}$ tests (b) Cell viability of block type.

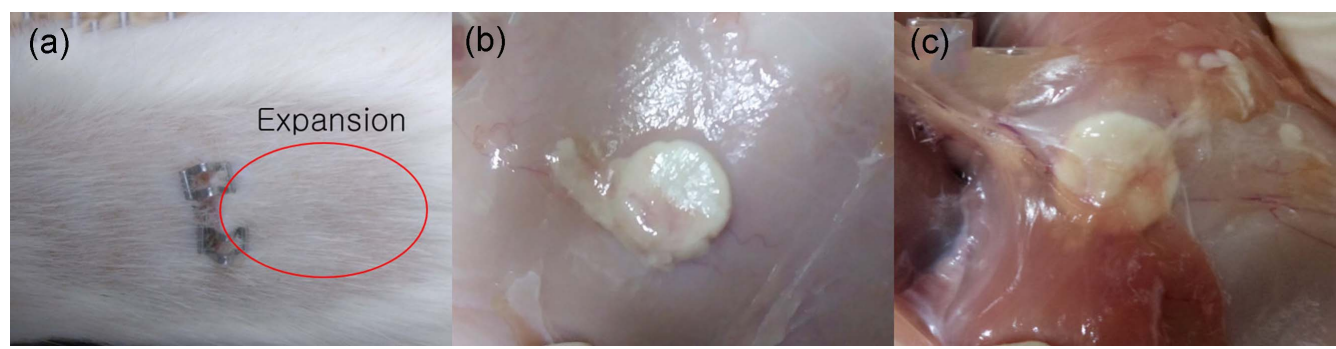

Fig. 12. Observation of inset block type (a) the back of rat at a week, (b, c) inset sample in sacrificed rat. 


\subsection{In vivo result}

At a week, the rat was observed with the naked eye. The back was quite swollen as shown Fig. 12(a). At 2 weeks, the rat was sacrificed and the back was incised. Swelling and edema were as shown in Fig. 12(b). On the subcutaneous level, no blood vessels were found, showing that 2 weeks is sufficient for recovery from the surgery and there is no side effect.

\section{Conclusions}

Several samples derived from paste form HAp/MC were tested in diverse ways in order to determine whether they were suitable for bone grafts. The standard by which the ratio of HAp to MC was chosen was the ability for the paste to stand vertically without slumping. Sample 2 fulfilled this criterion. The activation of the sample in SBF was proportional to the period of immersion. The SEM image of the sample showed that the degree of recrystallization reached its peak in 12 weeks. Nuclei of HAp seemed to grow over time. Gaps between the HAp/MC insert and the tooth filled in over time, showing that adhesion between tooth and sample was growing. Also, the hardness increased as time passed. Generally, the specimens had higher hardness than the samples inserted in teeth. The apparent porosity, water absorption, apparent specific gravity, and bulk specific gravity were $49.8 \%, 30.9 \%, 3.13577$, and 1.59094 , respectively. The tensile strength of the freeze-dried and sintered samples were 2.07 and 1.2 $\mathrm{MPa}$, respectively. The $\mathrm{pH}$ of the sample was 11.73 and the $\mathrm{pH}$ values of both water and $\mathrm{MC}$ were about 7 . The result of cell cytotoxicity was over the standard of $70 \%$ so that $\mathrm{HAp} / \mathrm{MC}$ can be regarded as nontoxic. The in vivo test shows that the sample does not cause any side effects.

This study shows that the paste form of HAp/MC can be used for bone grafts.

\section{Acknowledgments}

This work was supported by a 2-Year Research Grant of Pusan National University.

\section{REFERENCES}

1. T. Alberektsson and C. Johansson, "Osteoinduction, Osteoconduction Andosseointegration,” Eur. Spine J., 10 s96-101 (2001).

2. J. B. Park and J. D. Bronzino, Biomaterials: Principles and Application; Boca Raton: CRC Press, 2000.

3. R. C. Elkincs, P. E. Dawson, S. Goldstein, S. P. Walsh, and K. S. Black, "Decellularized Human Valve Allografts,"
Ann. Thorac Surg., 71 S428-32 (2001).

4. A. Lichtenberg, T. Breymann, S. Cebotari, and A. Haverich, "Cell Seeded Tissue Engineered Cardiac Valves Based on Allograft and Xenograft Scaffolds," Prog. Pediatr. Cardiol., 21 [2] 211-17 (2006).

5. P. V. Giannoudis, H. Dinopoulos, and E. Tsiridis, "Bone substitutes: An update," Injury, 36 S20-7 (2005).

6. S. T. Kao and D. D. Scott, "A Review of Bone Substitutes," Oral Maxillofac. Surg. Clin. North Am., 19 [4] 513-21 (2007).

7. F. Matassi, L. Nistri, D. C. Paez, and M. Innocenti, "New Biomaterials for Bone Regeneration," Clin. Cases Miner. Bone Metab., 8 [1] 21-4 (2011).

8. A. R. Vaccaro, "The Role of the Osteoconductive Scaffold in Synthetic Bone Graft," Orthopedics, 25 s571-78 (2002).

9. A. A. Campbell, "Bioceramics for Implant Coatings," Materialstoday, 6 [11] 26-30 (2003).

10. T. V. Thamaraiselvi and S. Rajeswari, "Biological Evaluation of Bioceramic Materials," Trends Biomater. Artif. Organs, 18 [1] 9-17 (2004).

11. P. N. de Aza, A. H. de Aza, and S. de Aza, "Crystalline Bioceramic Materials," ChemInform, 44 [3] 135-45 (2005).

12. D. Haverty, S. A. M. Tofail, K. T. Stanton, and J. B. Mcmonagle, "Structure and Stability of Hydroxyapatite: Density Functional Calculation and Rietveld Analysis," Phys. Rev. B, 71 [9] 094103 (2005).

13. G. Ma and X. Y. Liu, "Hydroxyapatite: Hexagonal or Monoclinic?," Cryst. Growth Des., 9 [7] 2991-94 (2009).

14. J. Reyes-Gasga, E. L. Martinez-Pineiro, and E. F. Bres, "Crystallographic Structure of Human Tooth Enamel by Electron Microscopy and X-Ray Diffraction: Hexagonal or Monoclinic?," J. Microsc., 248 [1] 102-9 (2012).

15. M. R. Wells, K. Kraus, D. K. Batter, D. G Blunt, J. Weremowitz, S. E. Lynch, H. N. Antoniades, and H. A. Hansson, "Gel Matrix Vehicles for Growth Factor Application in Nerve Gap Injuries Repaired with Tubes: A Comparison of Biomatrix, Collagen, and Methylcellulose," Exp. Neurol., 146 [2] 395-402 (1997).

16. S. Ghanaati, M. Barbeck, U. Hilbig, C. Hoffmann, R. E. Unger, R. A. Sader, F. Peters, and C. J. Kirkpatrick, "An Injectable Bone Substitute Composed of Beta-Tricalcium Phosphate Granules, Methylcellulose and Hyaluronic Acid Inhibits Connective Tissue Influx into its Implantation Bed in Vivo," Acta Biomater., 7 [11] 4018-28 (2011).

17. I. Toda, N. Shinozaki, and K. Tsubota, Hydroxypropyl Methylcellulose for the Treatment of Severe Dry Eye Associated with Sjogren's Syndrome," Cornea, 15 [2] 12028 (1996).

18. H. Shibata, T. Yokoi, T. Goto, I. Y. Kim, M. Kawashita, K. Kikuta, and C. Ohtsuki, "Behavior of Hydroxyapatite Crystals in a Simulated Body Fluid: Effects of Crystal Face," J. Ceram. Soc. Jpn., 121 [1417] 807-12 (2013). 